\title{
EXPERIÊNCIAS NO ESTÁGIO SUPERVISIONADO E MUDANÇA NAS TRAJE- TÓRIAS DE FORMAÇÃO E ATUAÇÃO DE DOIS GRADUANDOS EM LETRAS PORTUGUÊS-INGLÊS
}

\author{
Paula Graciano PEREIRA
}

\author{
Instituto Federal de Educação, Ciência e Tecnologia de Goiás
}

\begin{abstract}
RESUMO: Este artigo tem como objetivo apresentar e discutir as percepções e posturas de dois graduandos em Letras Português-Inglês relativas à docência em língua inglesa. Visamos, ainda, analisar como essas posturas e atitudes vão se modificando ao longo do semestre letivo e qual a influência das experiências vivenciadas na disciplina de estágio supervisionado no engendramento dessas mudanças. Este trabalho tem como pressupostos teóricos os estudos relativos à formação de professores de língua estrangeira numa perspectiva crítica (HAYAMA, 2008; OLIVEIRA; FIGUEIREDO, 2013; PEREIRA, 2013), sobretudo aqueles concernentes ao estágio supervisionado (BARROS; SILVA, 2011; COSTA, 2012; PIMENTA; LIMA, 2012). Adotando uma abordagem qualitativa de coleta e análise dos dados, este estudo de caso foi conduzido no primeiro semestre de 2010, em uma universidade pública. Foram utilizados como instrumentos de coleta de dados obervações de aulas com notas de campo, transcrições de gravações em áudio e vídeo de entrevista, sessões de orientação e planejamento e sessões reflexivas. Observamos que os participantes percorrem caminhos opostos em relação ao estágio supervisionado, indo do otimismo à desistência e, por outro lado, da negação de realizar as atividades ao comprometimento com a docência. Entre as conclusões obtidas, observamos que os participantes apresentam concepções, posturas e atitudes variadas e, muitas vezes, contraditórias, que sofrem influência de variáveis, sobretudo, de ordem pessoal.
\end{abstract}

PALAVRAS-CHAVE: formação de professores; estágio; mudança.

ABATRACT: This article aims at presenting and discussing the perceptions and attitudes about teaching English of two undergraduate students of Liberal Arts Portuguese-English. We also aim at analyzing how these perceptions and attitudes change throughout the semester and how the experiences lived in during internship may influence these changes. This study is based on works regarding language teachers' education in a critical perspective (HAYAMA, 2008; OLIVEIRA; FIGUEIREDO, 2013; PEREIRA, 2013), especially those concerning internship (BARROS; SILVA, 2011; COSTA, 2012; PIMENTA; LIMA, 2012). A qualitative approach was adopted in collecting and analyzing data. This case study was held in the first semester of 2010 at a public university. The data was obtained by means of class observation and field notes, and by transcribing video and audio recording of an interview, a mentoring and planning session, and reflective sessions. It was observed that the participants go different and opposite ways regarding their path throughout internship: on the one hand from optimism to giving up, and, on the other hand, from denial to commitment. The results pinpoint that the participants show contradictory conceptions, perceptions and attitudes which may be influenced by many variables, especially personal reasons.

KEYWORDS: teacher education; internship; change. 


\section{Introdução}

Este trabalho tem como campo a Linguística Aplicada Crítica, sobretudo os estudos acerca da formação de professores de línguas e da inserção na profissão docente (COSTA, 2012; FREIRE, 2011; HAYAMA, 2008; HUBERMAN, 2000; SZUNDY, 2012). Focalizamos as trajetórias de dois estudantes do curso de Letras Português-Inglês. Os objetivos deste estudo são identificar as percepções e posturas dos participantes acerca da docência em língua inglesa (LI); analisar como essas percepções e posturas vão se modificando ao longo do período letivo e; entender como a disciplina de estágio supervisionado contribui para essas mudanças.

O aluno-professor, durante o processo de formação inicial ${ }^{1}$ na universidade, é, em geral, pouco levado a refletir analítica e criticamente sobre os diversos aspectos que envolvem a docência (ALVARENGA, 1999; COSTA, 2012; HORIKAWA, 2004). O que se tem observado é uma "tendência a relegar às disciplinas de Prática de Ensino e Estágio Supervisionado as questões relacionadas a ensino e aprendizagem" (COSTA, 2012, p. 913-914). Para Costa (2012), Pimenta e Lima (2012), Reis (1999), Szundy (2012), Volpi (2001), entre outros autores, o processo de formação deve pressupor crescimento profissional e pessoal do professor. A mera exposição a teorias e métodos, sem uma reflexão crítica, pode tornar o docente um simples reprodutor do discurso alheio. No caso específico da LI, alguns fatores, como as questões sociopolíticas que envolvem o idioma, por exemplo, ampliam os conflitos e as dificuldades que os alunos-professores enfrentam na construção do fazer docente.

Esta pesquisa, portanto, se justifica pela necessidade de utilizar o estágio supervisionado como instância de construção de sentidos do fazer docente, dentro de uma perspectiva crítica de entendimento e análise da realidade material e sociopolítica que permeiam a LI e seu ensino-aprendizagem. Acreditamos que este trabalho pode contribuir para a reflexão acerca da formação de professores de LI no Brasil, assim como promover a discussão sobre a relevância deste assunto.

\section{Referencial teórico}

De acordo com Costa (2012, p. 918-919) "a licenciatura tem uma dupla perspectiva: o aluno aprende conteúdos, habilidades, procedimentos etc. e, ao mesmo tempo, deve aprender a ensinar o que aprendeu". Nesse sentido, juntamente com as demais disciplinas do curso de Letras, o estágio constitui-se como um fórum de construções significativas no processo de formação docente, contribuindo com o saber profissional do futuro professor. Ao cursar as disciplinas de estágio, o aluno-professor se envolve nas diversas atividades ligadas à docência para que possa experienciar a realidade da profissão em todos os seus aspectos. Durante o estágio, o acadêmico assume papel ativo em sua formação, pois sua experiência como professor será construída por ele mesmo, na interação com seus alunos, colegas e supervisores/orientadores. Não basta, portanto, colocar o estagiário para dar aulas. É também necessário propiciar-lhe condições e instrumentos para reflexão e análise sobre o que ele fez e viu

\footnotetext{
${ }^{1}$ Consideramos como formação inicial, ou formação pré-serviço, a etapa de estudos e preparação, na universidade, para o exercício da docência, antes da entrada na profissão. Compreendemos que o professor vem sendo formado desde suas primeiras experiências na escola, ou mesmo antes disso, no contexto familiar. Todavia, assim como Silva (2008), consideramos o curso de licenciatura como sua primeira instância oficial de formação profissional.
} 
para que então, se for o caso, ele modifique sua atuação, e assim continuamente (COSTA, 2012; SZUNDY, 2012).

Para Hayama (2008), o período de estágio deveria ser regido por uma sequência contínua de ação, reflexão e aperfeiçoamento. A autora tenta ilustrar esse percurso de formação por meio de um diagrama, que apresentamos a seguir:

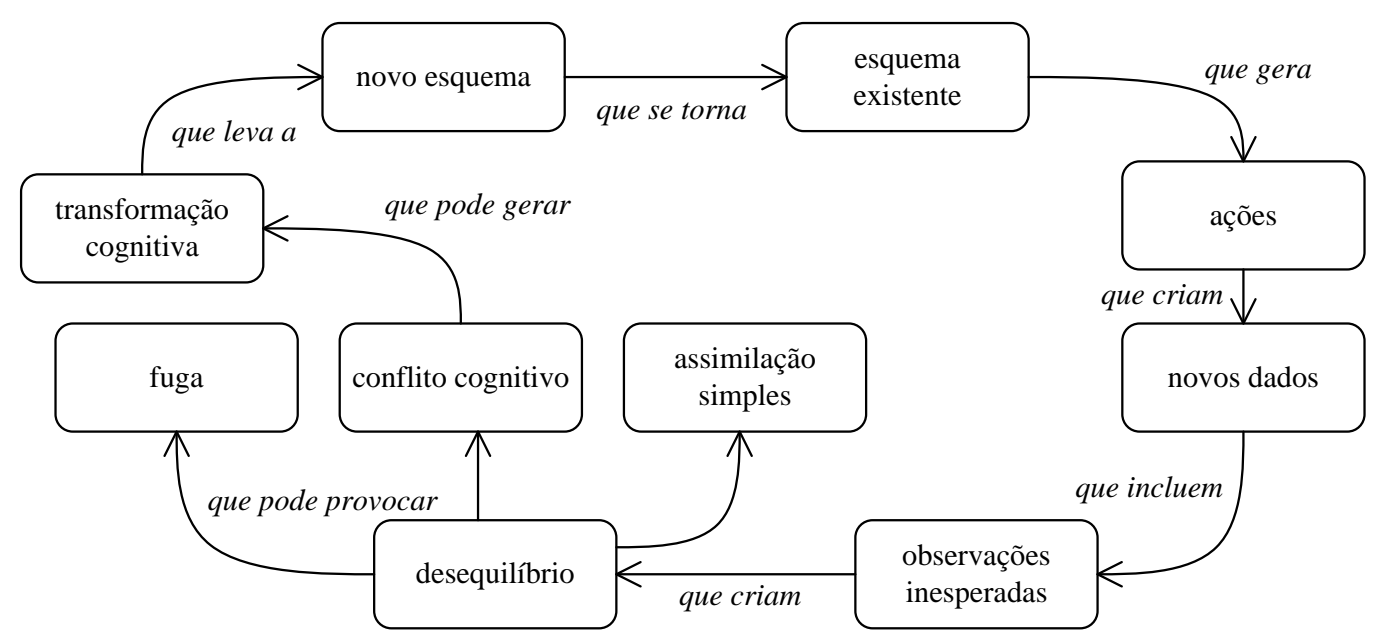

FIGURA 1: Modelo de reestruturação cognitiva a partir da experiência (Adaptado de HAYAMA, 2008)

Analisando o diagrama, podemos notar que não há início determinado, pois não há garantia de que um elemento irá gerar/engatilhar outro na sequência. A autora admite se tratar de uma sequência ideal, pois "o percurso por essa sequência não é automático e nem o primeiro elemento (a ação) dispara os demais" (HAYAMA, 2008, p. 43). Destacamos, entretanto, o elemento "desequilíbrio" como desencadeador de três possíveis ações/reações do professor: a) a fuga, quando a situação é interpretada como amedrontadora; b) a assimilação simples, quando a situação é considerada trivial ou não digna de atenção; e c) o conflito cognitivo, que pode levar à transformação cognitiva e à criação de novos esquemas e conceitos. A fuga e a assimilação encerram o conflito de forma definitiva e representam, muitas vezes, a volta ao estado de equilíbrio: o problema é solucionado ou simplesmente evitado. Por outro lado, o conflito cognitivo pode ocasionar ainda mais tensão e dúvidas e sua resolução exige do professor uma série de atitudes que, provavelmente, demandarão trabalho, tempo e energia.

Defendemos que o estágio é um momento decisivo na vida do acadêmico. É a inserção mediada do aluno-professor na realidade da escola, com o apoio de profissionais experientes, com orientação e assistência, o que nem sempre está disponível ao professor após sua entrada na carreira docente. É no estágio, prioritariamente, que o aluno-professor tira conclusões sobre sua escolha profissional e toma decisões quanto ao seu futuro. Oliveira e Figueiredo (2013) afirmam que o estágio é um momento crucial para que o aluno-professor estabeleça ou não uma identificação com a futura profissão. Para Freire (2011, p. 266), a experiência vivida no estágio "pode ser tão impactante que, por vezes, desestabiliza as concepções e representações dos futuros professores e abala - temporária ou definitivamente - a escolha profissional e a decisão de investir em uma carreira docente". No entanto, essas conclusões e decisões não são construções isoladas, ou seja, não se trata de uma elaboração meramente individual embasada somente nas opiniões e vontades do aluno-professor. A profissão docente é, e sempre foi, permeada por inúmeras representações sociais. 
Para Hayama (2008), tornar-se professor não é um processo linear de sobreposição de anos de estudo e anos de prática, mas um ciclo interminável de insegurança, incerteza, entusiasmo, expectativas, ações e transformações nas maneiras como o docente vê a si e ao mundo e se posiciona em relação a isso, como também argumenta Szundy (2012). Para esta autora, trata-se muito mais de um processo em espiral, com incontáveis idas e vindas em movimentos ascendentes que demonstram o crescimento do professor em formação e as constantes reformulações de suas perspectivas.

Nesse sentido, Huberman (2000) afirma que a entrada na profissão é marcada por dois processos: o de sobrevivência e o de descoberta. O primeiro diz respeito às dificuldades enfrentadas na realização dos trabalhos de professor, como a multiplicidade de tarefas, os conflitos e as dúvidas. Já o segundo aspecto se refere ao entusiasmo por finalmente ser professor, após tantos anos de estudo, e à energia e à disposição para encarar os desafios e as responsabilidades da profissão. Aparentemente contraditórios, os dois aspectos apontados pelo autor, são, em certa medida, complementares, pois doses de ambos são necessárias para que o docente tenha os pés no chão para enfrentar os problemas e gozar as alegrias que surgirão. Huberman vai ainda além e afirma que "com muita frequência, [...] os dois aspectos, o da sobrevivência e o da descoberta, são vividos em paralelo e é o segundo aspecto que permite aguentar o primeiro" (HUBERMAN, 2000, p. 39).

Gostaríamos de ressaltar que não há determinismo quanto às decisões e mudanças nas escolhas e na atuação do aluno-professor, pois diversos fatores contingentes podem influenciar os processos. Parece-nos que, pela própria fluidez e descontinuidade da vida em si, não é possível estabelecermos relações de causa e efeito ou, ainda, sequências rígidas de formação e atuação docente. Elementos diversos se interpõem e alteram o curso aparentemente natural dos fatos. Neste estudo, lidamos com as trajetórias de formação de dois alunos-professores que estão, logicamente, inseridos em contextos sócio-históricos, culturais e econômicos que atuam sobre suas decisões e ações. Neste artigo, refletimos sobre essas de idas e vindas, alterações e mudanças por que os participantes desta pesquisa passaram em seu processo de formação profissional.

\section{A pesquisa}

Participaram deste estudo dois acadêmicos do $8^{\circ}$ período do curso de Licenciatura em Letras Português-Inglês de uma universidade pública na região norte do país, em um campus localizado no interior do estado. No início da pesquisa, Bernardo tinha 23 anos e trabalhava como professor de inglês em uma escola de idiomas. Ele havia morado por oito anos nos EUA, onde sua família residia, com exceção de seu irmão, que morava na capital do estado. Bernardo viajava à capital com frequência e pretendia lá morar após o término do curso. Ele ambicionava cursar um mestrado e seguir a carreira docente no ensino superior. Boris, por sua vez, tinha 27 anos, vivia com a família em na cidade e trabalhava como técnico em informática. Ele nunca havia atuado como professor e, após o término do curso, iria viver em São Paulo com o irmão. Boris não pretendia ser professor, pois queria atuar no ramo de negócios de seu irmão.

Os dados focalizados neste artigo foram coletados no primeiro semestre letivo de 2010 e os graduandos foram acompanhados por mim - docente da turma, supervisora do estágio e pesquisadora - na realização do estágio tanto na universidade quanto na escola-campo em que atuaram como professores em duas turmas do segundo ano do ensino médio. Bernardo e Boris cursavam licenciatura dupla e, portanto, realizavam, concomitantemente, dois estágios. As 
leituras e atividades das demais disciplinas, somadas a uma carga horária total de 800 horas de estágio atuaram como fator de grande impacto na construção das percepções dos participantes sobre o estágio e, sobretudo, nas mudanças dessas percepções, como discutiremos a seguir.

\section{As percepções sobre o estágio supervisionado}

No início do semestre letivo, Boris e Bernardo deixam transparecer suas expectativas quanto ao estágio: esperam sua conclusão o mais rápido possível, em poucos dias, ou gostariam, melhor ainda, que ele fosse totalmente eliminado. $\mathrm{O}$ trecho a seguir mostra este ponto de vista dos estudantes:

\section{[1]}

\section{[Trecho de entrevista]}

Bernardo: Vai poder pegar quantas turmas de inglês?

Pesquisadora: No máximo duas.

Bernardo: Aff... ((expressão de descontentamento)) São 21 aulas, né? Vai demorar...

Pesquisadora: Mas por que você quer correr com o estágio?

Bernardo: Para acabar logo. Tem o estágio de português também. Tem literatura inglesa.

Pesquisadora: Mas se pegar muitas turmas, não dá tempo de vocês planejarem e desenvolverem um trabalho. Dá 3 aulas em cada turma e pronto. Não dá para desenvolver nada.

Bernardo: Eu sei, mas pelo menos acaba logo. (...)

Boris: Tudo bem. Mas seria melhor se a gente pulasse direto pra julho. ((risos))

Pesquisadora: Mas que ansiedade é essa? Por que você quer pular o semestre inteiro?

Boris: Para formar logo! Estou doido para terminar isso!

Bernardo: Nem me fale!

Sabemos que o estágio é um processo longo e complexo, mas essencial à formação do futuro professor, por oferecer a ele oportunidades de se construir como profissional, de conhecer as rotinas e meandros da profissão. Contudo, a postura de Boris e Bernardo indica que ambos percebem o estágio como parte do processo de formação do ser professor, mas, ao ter que realizá-lo, ele se apresenta, para os participantes, apenas como uma tarefa a ser cumprida, uma formalidade, um requisito para a formatura. Tal fato não implica que Boris e Bernardo não reconheçam que o estágio é um processo importante em sua formação, mas ressaltam que se trata de uma tarefa cansativa. Podemos perceber que os estudantes se encontram em conflito entre o que consideram necessário e relevante para seu futuro profissional, e o desgaste de cumprir o que o estágio exige. Entre o discurso e a execução, parece existir um desencontro. Bernardo, especialmente, demonstra ter consciência da complexidade do estágio, porém se recusa a assumir e executar os procedimentos necessários, tais como planejar aulas, por exemplo. O excerto a seguir ilustra um momento de uma sessão de orientação e planejamento em que Bernardo comenta acerca do fato de a dupla não estar planejando as aulas ministradas na escola-campo:

[2]

[Trecho de sessão de orientação e planejamento]

Pesquisadora: Vocês já planejaram a aula de amanhã? 
Bernardo: Tem um mês que a gente não planeja aula. ((riso demonstrando constrangimento)) É sério. A gente chega lá e dá aula.

A desconsideração da importância e da necessidade do planejamento de aula demonstra a negativa de Boris e Bernardo de assumir seu papel ativo na construção de seu fazer profissional. Como defendem Freire (2011), Santos H. (2005), Silva (2008), o estágio contribui com o fazer profissional do futuro professor, por se tratar não apenas de um espaço para a aplicação de teorias e métodos estudados na sala de aula. O licenciando deve assumir papel ativo em sua formação, pois sua experiência como professor será construída por ele mesmo. Todavia, Bernardo e Boris parecem se recusar a desempenhar de maneira ativa seu papel nesta construção.

O não planejamento das aulas demonstra certa falta de comprometimento dos participantes com sua própria formação e com os seus alunos. O planejamento é importante não só para esquematizar as etapas e ações instrucionais, mas para levar o professor a refletir sobre seu próprio fazer pedagógico, e se engajar na futura profissão. Por outro lado, planejar aulas se apresenta como uma responsabilidade extraclasse, que pode onerar o professor e sobrecarregá-lo. Como os participantes tinham outras atribuições e atividades além da disciplina de estágio, essa sobrecarga e esse desgaste já estavam sendo antecipados ainda na fase de formação inicial. O estágio se torna, para Boris e Bernardo, um desafio opressor.

Os estagiários parecem estar passando pelo processo de sobrevivência descrito por Huberman (2000). Para o autor, trata-se do reconhecimento e do enfrentamento das dificuldades da profissão. Todavia, ao se deparar com a quantidade e a complexidade do trabalho a ser feito, Boris e Bernardo fogem de suas obrigações, ao significarem o planejamento como tarefa difícil e trabalhosa demais. Para Hayama (2008), o professor pode interpretar uma situação de desequilíbrio como amedrontadora, um desafio além de sua capacidade. A entrega dos planos não era exigida a cada aula, mas eles deveriam constar no portfólio de estágio, entregue ao final do semestre letivo. Diante disso, Bernardo e Boris executavam as aulas sem planejá-las formalmente, desconsiderando esta atividade, e resolvem o conflito da situação de desequilíbrio simplesmente deixando de lado o exercício de planejar.

Já o projeto de ensino, temática do próximo excerto, era uma tarefa obrigatória que deveria ser entregue em data pré-determinada. O projeto de ensino configura-se como parte importante para a construção de aulas mais significativas e que atendam às necessidades dos alunos, contemplando conteúdos gramaticais, lexicais e também de cunho sociocultural. No entanto, ao se depararem com a necessidade da elaboração do projeto, Boris e Bernardo assumem a postura de assimilação simples, trivializando a tarefa e considerando-a como não digna de atenção e esforço. $\mathrm{O}$ excerto a seguir nos apresenta o posicionamento de Bernardo:

\section{[3]}

\section{[Trecho de sessão de orientação e planejamento]}

Bernardo: O que eu vejo que está acontecendo é o seguinte: você falou em março que a gente ia ter que montar o projeto. Só que a gente não fez, por $n$ motivos. Só que, por que eu estava tranquilo? Eu achei que a gente só ia entregar o projeto no fim do semestre. Aí você chega e fala que tem que entregar essa meleca aqui. Tipo, eu faria o negócio numa noite, entendeu? E, assim, saiu the flash. Mas saiu alguma coisa. (...) Assim... O projeto saiu pura e exclusivamente para suprir...

Pesquisadora: Para entregar.

Bernardo: Para entregar. Exato. Exato.

Ao se referir ao projeto de ensino como "meleca", Bernardo o desvaloriza e o considera como uma tarefa simples, passível de ser elaborada em uma noite, ou seja, que não merece 
sua atenção e esforço. Embora se trate de uma exigência do curso prevista no programa de aulas entregue aos alunos no início do semestre, o acadêmico se exime do trabalho de ter que pensar, estudar e refletir para elaborar um projeto e aplicá-lo. Podemos perceber que Bernardo assume uma postura de assimilação simples, (Hayama, 2008) para a solução dessa situação de desequilíbrio, por meio da trivialização e/ou desconsideração da tarefa. Nesse sentido, percebemos, ainda, que há um descompromisso com o estágio, com os alunos e com a sua própria formação profissional. Para Bernardo, o estágio como um todo e as tarefas a ele ligadas, como o planejamento de aulas e a elaboração do projeto de ensino, por exemplo, representam simples formalidades a serem cumpridas e ultrapassadas visando a um alvo maior e realmente importante: a formatura. Embora consciente da relevância do estágio no processo de formação do professor e apesar de possuir razoável conhecimento teórico e capacidade de reflexão, o estudante se nega a passar pelas etapas e tarefas do estágio, preferindo se eximir de executálas ou cumprindo-as apenas para ser aprovado na disciplina. Ao se verem obrigados a enfrentar problemas reais, cansaço, desgaste e trabalho, a postura dos acadêmicos oscila entre a negação total, como a fuga proposta por Boris no excerto 1, ao afirmar que gostaria de pular todo o semestre, e a assimilação simples da trivialização das tarefas propostas e necessárias à realização do estágio. Essa postura de cansaço e desânimo de Bernardo é justificada pelo acadêmico devido a questões de sua vida pessoal, como podemos observar nos excertos a seguir:

[4]

\section{[Trecho de sessão reflexiva]}

Pesquisadora: Hoje os meninos estavam a mil, heim! O que vocês acharam da aula?

Boris: Achei boa, divertida. Teve barulho, né, mas normal. Eles estavam empolgados.

Pesquisadora: E você, Bernardo? O que você achou?

Bernardo: Achei boa também. Whatever.

Pesquisadora: Como assim "whatever"? Você não gostou da aula?

Bernardo: Ai, Paula... ((suspira)) (...) Eu não aguento mais essa vida! Eu arrasto a semana inteira só esperando o fim de semana para poder ir para [a capital]. Eu quero acabar isso logo e ir embora de vez.

Pesquisadora: Calma... Que desespero é esse? Faltam uns 2 meses só. Aí vocês se formam. (...)

Bernardo: A gente só está fazendo o estágio porque é obrigado. Só porque você observa as aulas. Eu quero é acabar logo com isso. Viver minha vida. Eu quero viver!

O cansaço de Bernardo faz com que ele se distancie do processo de estágio. O acadêmico não se mostra mais preocupado com o modo como as aulas estão acontecendo, tampouco com nenhum outro aspecto de sua formação profissional no estágio. Bernardo não está disposto a pensar sobre a aula dada, analisar o que foi feito. $\mathrm{O}$ estudante quer apenas que o estágio, assim como o curso de Letras em si, terminem para que ele possa retomar o que considera como a vida normal.

Bernardo parece vivenciar apenas um dos processos descritos por Huberman (2000), o da sobrevivência, visto que apresenta sentimentos bastante negativos, como pessimismo, desânimo e indiferença. $\mathrm{O}$ acadêmico experiencia e enfrenta as dificuldades e o desgaste da profissão mesmo ainda na fase de formação pré-serviço, mas parece não estar passando pelo processo da descoberta, prioritariamente a que o estágio se destina. A descoberta, como proposto por Huberman (2000), é responsável pela motivação e pelo ânimo que o professor precisa ter para superar os problemas e percalços do processo de sobrevivência e, também, para aproveitar as alegrias que a docência oferece. Bernardo parece nem sequer vislumbrar essas alegrias e o foco de sua atenção e energia está totalmente voltado para o desgaste e o sofrimento que realizar o estágio lhe causa, em oposição à felicidade que ele projeta para após o término do 
curso, a possibilidade de "viver a vida". A ausência da descoberta leva à desmotivação de Bernardo e à sua mudança de posturas ao longo do semestre letivo: de aluno-professor dedicado, otimista e motivado, a cansado, pessimista e desanimado. $\mathrm{O}$ estágio passa de processo importante e necessário a obrigação enfadonha e cansativa.

Diante do descomprometimento de Bernardo com o estágio, Boris assume a postura de líder da dupla e passa, então, a se responsabilizar pelo planejamento de todas as aulas e pela elaboração do projeto de ensino. O trecho a seguir nos apresenta essa postura do estudante:

[5]

\section{[Trecho de sessão de orientação e planejamento]}

Boris: De hoje para amanhã tem que planejar.

Bernardo: Ai, meu Deus! Estou cansado dessa vida de parir! Cada dia é um parto nessa faculdade!

Pesquisadora: Não estou falando para vocês fazerem um plano de aula formal agora. Mas, pelo menos, terem uma ideia.

Boris: Ok. Então eu vou bolando os exemplos e faço os papeizinhos com as palavras. Você compra as balinhas e leva amanhã. E a Paula fica online ajudando. Eu vou te mandar as frases e você corrige, ok?

Bernardo: Eu vou me jogar da ponte!

Boris: Vai estragar a ponte. ((risos))

Com base nas observações das aulas ministradas por Boris e Bernardo, é possível perceber que, inicialmente, Boris atuava em sala menos que Bernardo, que conduzia a maioria das tarefas nas aulas. No entanto, podemos perceber que Boris vai, gradativamente, assumindo um papel muito mais ativo na dupla e no próprio estágio, e passa a definir as funções que cada um executará no processo, inclusive as minhas, como professora orientadora. Para Bernardo, ele designa as tarefas que considera menos trabalhosas e desgastantes, levando em conta a condição do amigo. Boris poderia ter se recusado a continuar trabalhando com Bernardo, saindo da dupla ou procurando outro parceiro, mas não o fez. Bernardo, por sua vez, assume o papel de executor das aulas planejadas por Boris.

Por se considerar menos proficiente que Bernardo e menos competente para atuar como professor de inglês, Boris se espelhava no colega e deixava-o conduzir as aulas, tomando o turno apenas em situações de correção de frases ou divisão de grupos, por exemplo. No entanto, sua atitude mudou quando ele se viu responsável pela dupla e, consequentemente, pela conclusão bem-sucedida do estágio. Embora também tivesse a mesma perspectiva de Bernardo em relação a acelerar o término do curso, Boris assumiu uma postura oposta à do colega, empenhando-se ainda mais no cumprimento de suas tarefas. O que podemos concluir é que Boris parece ter se imbuído do processo, tomado seu lugar ativo na construção de seu fazer pedagógico. Para Boris, o estágio passa a ser, de fato, formação e reflexão, ao passo que Bernardo se nega a tomar parte no processo.

Enquanto Boris tenta organizar as ideias e elaborar um plano informal para a aula do dia seguinte, Bernardo não oferece nenhuma ajuda ao colega. Diante da situação de desequilíbrio de ter que definir o foco da aula e planejar os exemplos, Bernardo opta pela fuga, como descrita por Hayama (2008). Por outro lado, diante do conflito e vendo-se sozinho perante a situação de desequilíbrio, Boris demonstra realizar os processos de conflito e transformação cognitiva. Para Hayama (2008), quando o professor opta por enfrentar um problema e pensar sobre ele, há conflito cognitivo entre o que o docente sabe e se julga capaz de fazer e o que é necessário que ele faça. Esse conflito tende a levar a uma transformação cognitiva com a criação de novos esquemas e conceitos. O professor, assim, reconstrói e ressignifica seu conhecimento e sua prática. Boris parece percorrer este processo no momento da tomada de decisão sobre o que fazer quanto à aula do dia seguinte. 
Podemos afirmar que esse processo de conflito e transformação cognitiva se repete e se estende para outras instâncias da formação profissional de Boris, não somente em relação ao planejamento de aulas. $\mathrm{O}$ acadêmico assume uma postura ainda mais comprometida e engajada, não mais como auxiliar de Bernardo nas tarefas da sala de aula, como antes, mas realmente como estudante em formação para se tornar professor. Boris passa a participar ativamente de todas as etapas do estágio, responsabilizando-se por todo o planejamento, como já mencionado, atuando como instrutor de fato dos conteúdos nas aulas e como mediador de conflitos em inúmeras situações, engajando-se nas reflexões e ressignificando sua prática e seu conhecimento.

Em uma aula em que os alunos formulavam frases comparando pessoas, houve uma discussão sobre homossexualidade, na qual os estudantes se exaltaram ao emitir suas opiniões. Bernardo, por sua vez, também se exaltou e acabou discutindo com alguns alunos, com tom de voz alterado. Diante do conflito na sala de aula, Boris interveio e tentou mediar a discussão, acalmando os ânimos e direcionando a conversa para a importância do respeito às diferenças e do combate à discriminação.

Embora mais fluente e experiente, pois já atuava como professor de inglês há alguns anos, Bernardo se viu diante de um conflito em sala de aula que não conseguiu resolver. $\mathrm{O}$ estagiário não assumiu seu papel de mediador da discussão, como professor. A ocorrência na sala de aula ultrapassou o âmbito do meramente linguístico e, diante disso, Bernardo se sentiu inseguro. Ele estava acostumado a um contexto de ensino, no curso de inglês onde trabalhava, em que esses assuntos não são abordados. Provavelmente devido a esses fatores, ele se sentiu perdido quanto à situação de conflito e percebeu a discussão acerca da homossexualidade como não relacionada à aula e, então, deixou de desempenhar sua função como professor, por não saber o que fazer.

Ao perceber o conflito e as dificuldades de Bernardo em lidar com o problema, Boris intervém e conduz a discussão para o nível da reflexão. Percebemos claramente, neste momento, que o estagiário se assume como professor responsável pelos alunos e pela aula. Diferentemente do colega, ele percebe a sala de aula como um espaço vivo, uma arena de conflitos e formação de pontos de vista diferentes, como também argumentam Jordão e Fogaça (2012), Pennycook (1998), Pessoa (2011) e Pessoa e Urzêda-Freitas (2012).

Após o encerramento desta aula em questão, Bernardo e Boris quiseram comentar os acontecimentos e expressar suas opiniões a respeito das atitudes dos alunos. $\mathrm{O}$ exemplo a seguir nos mostra as reflexões dos estagiários sobre a aula:

[6]

\section{[Trecho de sessão reflexiva]}

Bernardo: Na hora em que ela falou aquilo, eu me descontrolei. E eu não podia ter perdido o controle daquele jeito.

Boris: Assim, ali a gente tem que trabalhar com a opinião deles, não com a nossa. A nossa tem que influenciar, mas a gente tem que ouvir a deles e respeitar. Não debater cara a cara com o aluno.

Bernardo: Mas aí é que está, eu tenho esse problema. (...) Quando eu vou discutir com alguém eu não fico pensando se a minha opinião vai influenciar, se só pelo fato de eu ser professor vai fazer com que aquela pessoa mude de ideia.

Boris: Mas o professor não tem esse poder. Não dá para chegar e dizer "Olha, gente, esse é o certo.".

Bernardo: Eu defendo o meu ponto de vista do jeito que ela defendeu o dela. 
Boris: Eu sei, mas eu falo assim... Por exemplo... Teve dois momentos em que você discutiu com pessoas, fora a sala. A sala ficou num canto e você discutindo com as alunas. E não adianta. Numa discussão dessa, pesada, pode debater cinco aulas que não vai mudar de opinião assim. Não chega a lugar nenhum. $\mathrm{O}$ interessante seria pegar a opinião deles, a opinião deles a favor e contra, e aí sim que nós íamos mediar.

Bernardo: Mediar.

Boris: E outra coisa, quando a gente quer ser professor, na aula assim, quando a gente quer falar alguma coisa, quer conversar ou quer discutir algum ponto, a gente não chega e fala. A gente lança a pergunta. Entendeu? Deixa aquela dúvida na cabeça deles. Igual quando ela falou assim "Ah, eu sou contra.". Aí faz uma pergunta para ela, para ela na hora pensar.

Percebemos, aqui, como os sentidos atribuídos por Bernardo à LI e ao seu ensinoaprendizagem permeiam suas percepções acerca do estágio e do que significa ser professor de inglês. Bernardo não se vê como professor, mas como uma pessoa discutindo com outra sobre uma questão polêmica, ambas defendendo ardentemente seus pontos de vista. A noção de contexto de ensino-aprendizagem o escapa, pois, para ele, discussão não é ensinoaprendizagem, mas um momento de embate de ideias. Por outro lado, Boris assume uma postura muito mais reflexiva, sugerindo, inclusive, mudanças e alternativas. Para ele, as discussões podem ser um instrumento de conscientização dos alunos, uma forma de levá-los a pensar e a reconstruir suas opiniões. Essa postura de Boris se alinha à proposta de ensinoaprendizagem crítico de inglês, como defendido por Urzêda-Freiras (2012, p. 92), ao afirmar que

não basta apenas ouvir um(a) aluno(a) expressar a sua opinião: é preciso levá-lo(a) a repensar os seus valores, as suas crenças e as suas práticas em uma perspectiva mais crítica e transgressiva, que problematize os discursos dados como naturais na sociedade; é preciso levá-lo(a) a refletir sobre como esses valores, crenças e práticas se articulam com a manutenção do preconceito e da discriminação, muitas vezes contra si mesmo(a).

Nesse sentido, é necessário que o professor se prepare teórica e didaticamente para lidar com os conflitos que certamente emergirão em uma aula crítica de inglês. É preciso que o professor tenha elementos e condições de não só instigar os alunos a expressar e repensar seus pontos de vista, mas também que ele esteja preparado para conduzir esse processo de reflexão e tomada de consciência. E para que isso aconteça, é importante que o professor esteja, ele próprio, consciente do seu e dos inúmeros outros discursos que perpassam e constituem a aula de LI.

Como podemos perceber, as percepções e posturas de Bernardo e Boris são constantemente construídas e reconstruídas ao longo do semestre letivo. A espiral ascendente proposto por Szundy (2012) parece bastante nítido no processo de formação profissional dos participantes, uma vez que podemos observar os inúmeros movimentos de idas e vindas, avanços e retomadas pelos quais Bernardo e Boris passam.

\section{Considerações finais}

As percepções e posturas de Bernardo mudam drasticamente ao longo do semestre. De inicialmente otimista e determinado, ele vai se mostrando cada vez mais pessimista, cansado, desanimado e indisposto à medida que o semestre avança. Suas certezas e esperanças vão sendo substituídas por dúvidas e dificuldades que o frustram e o deixam descrente. Seu en- 
volvimento com as aulas na escola-campo diminui e ele passa a somente executar as tarefas planejadas por Boris. Essa postura de recusa e descrença, contudo, vai além do estágio. Após a formatura, Bernardo desiste da carreira docente e passa a trabalhar em uma repartição pública na capital do estado, realizando função burocrática. Ele justifica a mudança de profissão por questões de ordem financeira e pessoal: a possibilidade de ganhar mais e trabalhar menos; a não necessidade de trabalhar em casa e nem aos finais de semana; a oportunidade de realizar parte de seus sonhos e anseios materiais.

Já Boris parece trilhar o caminho contrário ao de Bernardo. Inicialmente muito determinado a terminar tudo o mais rápido possível para mudar-se para São Paulo, ele vai, ao longo do semestre, assumindo uma posição mais disposta e interessada. Seu comprometimento com as aulas na escola-campo aumenta e ele assume a responsabilidade pelo planejamento das aulas e confecção dos materiais didáticos. Essa mudança de Boris também se estende para além do estágio. Após regressar de São Paulo, já graduado, ele ingressa na carreira docente e passa a trabalhar em um centro de recuperação de menores infratores, onde atua como professor de diversas disciplinas. Boris justifica sua escolha por fatores financeiros e pessoais: o salário considerado bom; a estabilidade financeira e emocional; a possibilidade de viver perto da família; e, sobretudo, a oportunidade de ser educador e contribuir para a formação de jovens marginalizados.

Podemos perceber que inúmeros fatores, muito além do alcance da universidade, atuaram e colaboraram para a construção e a transformação das percepções dos participantes. Tornar-se professor de inglês é um processo muito abrangente e intrincado, que perpassa quase todos os planos da vida do indivíduo, tais como: financeiro, pessoal, familiar e ideológico, por exemplo. Não podemos afirmar categoricamente que o estágio e os conhecimentos e as experiências construídos ao longo desse período tenham determinado o fato de Boris ter se tornado professor de inglês e Bernardo ter escolhido exercer outra profissão, mesmo tendo sido formado para a docência.

Parece-nos que, pela própria dinâmica da vida em si, não é possível estabelecermos relações de causa e efeito quanto à entrada e/ou desistência da profissão. Elementos diversos se interpuseram e interferiram no curso dos fatos. Porém, podemos afirmar que as discussões e reflexões construídas através de inúmeras formas de mediação, ao longo da disciplina de estágio supervisionado, contribuíram para a tomada de consciência acerca do que os dois participantes pensam e sentem a respeito de ser professor. Não nos cabe avaliar ou julgar as percepções e posturas dos participantes deste estudo. A formação de professores é um processo complexo, cíclico e contínuo de reflexão e ressignificação de sentidos, atitudes e ações. Além disso, sabemos que a vida é fluida e descontínua e que a experiência humana é construída em processos de idas e vindas, avanços e retrocessos, os quais não significam, necessariamente, fracasso.

\section{Referências}

COSTA, E. G. M. Práticas de letramento crítico na formação de professores de línguas estrangeiras. Revista Brasileira de Linguística Aplicada, v. 12, n. 4, p. 911-932, 2012.

FREIRE, M. M. O estágio de observação e a formação docente sob a perspectiva da complexidade. In: SILVA, K. A.; DANIEL, F. G.; KANEKO-MARQUES, S. M.; SALOMÃO, A. C. B. (Org.). A formação de professores de línguas: novos olhares. V. 1. Campinas, SP: Pontes, 2011. p. 265-284. 
HAYAMA, P. M. Alunos-professores e professores-alunos: o trabalho em grupo no estágio supervisionado. 2008. Dissertação (Mestrado em Educação). Universidade de São Paulo, Faculdade de Educação, São Paulo, 2008.

HUBERMAN, M. O ciclo da vida profissional de professores. In: NÓVOA, A. (Org.). Vidas de professores. Porto: Porto Editora, 2000. p. 31-61.

JORDÃO, C. M.; FOGAÇA, F. C. Critical literacy in the English language classroom. D.E.L.T.A., v. 28, n. 1, p. 69-84, 2012.

OLIVEIRA, H. F.; FIGUEIREDO, F. J. Q. O que o "não" nos diz: narrativas de licenciados em Letras que não se tornaram professores. In: OLIVEIRA, H. F.; BICALHO, P. S. S.; MIRANDA, S. C. (Org.). Educação e diversidade: múltiplos olhares. Anápolis: Universidade Estadual de Goiás, 2013. p. 111-138.

PENNYCOOK, A. A linguística aplicada nos anos 90: em defesa de uma abordagem crítica. In: SIGNORINI, I; CAVALCANTI, M. C. (Org.). Linguística aplicada e transdisciplinaridade. Campinas, SP: Mercado das Letras, 1998. p. 23-49.

PESSOA, R. R. Formação crítica de professores de línguas estrangeiras. In: SILVA, K. A.; DANIEL, F. G.; KANEKO-MARQUES, S. M.; SALOMÃO, A. C. B. (Org.). A formação de professores de línguas: novos olhares. V. 1. Campinas, SP: Pontes, 2011. p. 31-47.

PESSOA, R. R.; URZÊDA-FREITAS, M. T. Ensino crítico de línguas estrangeiras. In: FIGUEIREDO, F. J. Q. (Org.). Formação de professores de línguas estrangeiras: princípios e práticas. Goiânia: Editora da UFG, 2012. p. 57-80.

SANTOS, H. M. O estágio curricular na formação de professores: diversos olhares. 2005. Disponível em: <www.anped.org.br/reunioes/28/textos/gt08/gt0875int.doc>. Acesso em: 02 maio 2013.

SILVA, B. R. S. Estágio supervisionado de LE: um estudo de caso sobre a formação universitária de professores de inglês na UFG. 2008. Tese (Doutorado em Letras e Linguística) - Faculdade de Letras, Universidade Federal de Goiás, Goiânia, 2008.

SZUNDY, P. T. C. Zones of conflicts and potentialities in the process of becoming an EFL teacher. Revista Brasileira de Linguística Aplicada, v. 12, n. 3, p. 511-531, 2012.

URZÊDA-FREITAS, M. T. Educando para transgredir: reflexões sobre o ensino crítico de línguas estrangeiras/inglês. Trabalhos em Linguística Aplicada, v. 51, n. 1, p. 77-98, jan./jun. 2012. 